\title{
Wittgenstein ON FREUD’s PsychoANALYSis
}

\author{
MARCo ANTONio Franciotti
}

\begin{abstract}
In this article, I endeavor to analyze Wittgenstein's remarks on certain aspects of Freud's theory in the hope to show that his criticism can be epistemologically fruitful to pinpoint some insurmountable theoretical difficulties in the metapsychological aspect of psychoanalysis, especially with regard to Freud's insistent remarks that his deep psychology must be viewed as a scientific approach of psychic phenomena.
\end{abstract}

Keywords: Psychoanalysis; science; language; determinism; metaphysics.

\section{Introduction}

As usual, Wittgenstein offers just scattered remarks about Freud. It is possible, however, to gather them together by addressing three major recurring reservations on Freud's scientific aspirations to his deep psychology.The first has to do with the fact that Freud gets entangled in a kind of mythology or metaphysics. The second stems from Freud's remarks that truth of psychoanalytical explanations is ultimately dependent upon the assent of the patient. Considering that it requires some sort of access to the patient's own mental states, such a criterion carries an unpalatable subjective component and falls short of a proper basis for a scientific explanation. Finally, the third restriction involves Freud's alleged conflation between reason-based and causebased explanations. According to Wittgenstein, Freud uses only the former kind of explanations and treats it as though it were the latter. In so doing, Freud would have distanced himself from science even further.

Let us go through them one by one from now on.

\section{Freud's mythology}

A fruitful way of highlighting the metaphysical aspects of psychoanalysis is to take account of the relationship between the conscious and the unconscious. Freud argues that it is possible to translate the language of the unconscious into that of the conscious mind. In his own words, "one can state that psychoanalytical interpretations are, first and foremost, translations from a strange method of expression to another, more familiar one" (Freud 1913, p.403). Wittgenstein contends that such a translation can only be carried out if we hold a metaphysical conception of the mind. Once this is done, we will be able to emphasize the mythological character of Freud's metapsychology.

Principia 21(1): 1-12 (2017).

Published by NEL — Epistemology and Logic Research Group, Federal University of Santa Catarina (UFSC), Brazil. 
One of the main tenets of psychoanalysis is to explain the language of the unconscious:

When we interpret dreams, we merely translate a certain content of thought (the so called latent oniric thoughts) of dream language into our awaken life. In this way, we learn the peculiarities of this oniric language and ascertain that it belongs to a highly arcaic system of expression. (Freud 1913, p.403)

When we deal with the unconscious, we inevitably resort to the language that we use in our every day life, to wit, the language of the conscious mind. The question arises as to whether this task is feasible, provided that the unconscious is very different from the conscious. Wittgenstein claims that there is no such a thing as a language of the unconscious that is thoroughly unique and thus completely different from the language of the conscious. The reason is that language is always translatable. If we grant that the analyst can make the translation from the unconscious to the conscious, the contrary is by no means the case:

Suppose you look on a dream as a kind of language. A way of saying something, or a way of symbolizing something. There might be a regular symbolism, not necessarily alphabetical — it might be like Chinese, say. We might then find a way of translating this symbolism into the language of ordinary speech, ordinary thoughts. But then the translation ought to be possible both ways. It ought to be possible by employing the same technique to translate ordinary thoughts into dream language. As Freud recognizes, this never is done and cannot be done. So we might question whether dreaming is a way of thinking something, whether it is a language at all (Wittgenstein 1982, p.6).

If it is not possible to translate the conscious language into the alleged unconscious one, the unconscious is not linguistic. Therefore, Wittgenstein contends, Freud's purpose to translate the unconscious language seems unattainable. Wittgenstein rejects Freud's idea that the language of the unconscious is unique and therefore untranslatable into our every day language. If we can translate $A$ into $B$, we must be able to translate $B$ into $A$ as well; but that is not allowed by Freud.

According to Wittgenstein, the unconscious is conceived of by Freud as a very distinctive part of the mind that cannot be equated with the conscious one. Freud, however, seems to be aware of this difficulty when he clarifies that psychoanalytic observations are carried out "with the help of gaps in the sequences of 'psychic' occurrences: we bridge those gaps by making plausible deductions and by translating them into conscious material" (Freud 1940, p.81; my italics). As Gellner puts it, the unconscious "speaks our language, but like a drunk person" (Gellner 1988, p.182). The unconscious language can be viewed as highly rudimentary, but "close enough to our daily language so as to exchange coded messages with the conscious mind"

Principia 21(1): 1-12 (2017). 
(Gellner 1988, p.182). However, since Freud refuses to accept the opposite translation, i.e., that one from the conscious language into the unconscious one, we are left with the following impasse: either there is a language of the unconscious, which implies that the so called unconscious is nothing but a manner of speaking and therefore can be reduced to the language of the conscious mind; or there is no language of the unconscious, which implies that psychoanalytic endeavors to unravel and explain the unconscious can never be achieved.

One could devise a way to vindicate Freud as follows. There is obviously a lot of similarities between dream imagery and linguistic signs. Dreams are made out of bundles of images; to deny a image of its symbolic character is a grave mistake. However, this is question begging. Wittgenstein concedes that "dream imagery looks like a language" (Wittgenstein 1982, p.4), but that is not the point. What is at stake is not the possibility of a image-based language; Wittgenstein is pointing to a very controversial and unpalatable presupposition imbedded in Freud's overall strategy, to wit, the idea of a pre-existing language that would impugn other interpretations (cf. Bouveresse 1995, p.110). This is confirmed by Freud:

Through several associations carried out by the patient, we would arrive at the knowledge of a thought structure that could not any longer be described as absurd or confusing, (a knowledge) that would present itself as a completely valid psychic product the dream of which was merely a distorted, abbreviated and poorly understood translation. (Freud 1925b, p.69).

Furthermore, Freud utilizes the jigsaw puzzle metaphor to explain the certainty and validity of psychoanalytical explanations:
At the end of the day, what validates the analyst's view is precisely the com- plexity of the problem in front of him, just like the solution to a jigsaw puzzle. A colorful figure, glued to a thin layer of Wood (...) is cut into pieces (...). If one can reorganize those fragments (...) so that the resulting figure can have meaning (...), If all those conditions are met, then we know that the puzzle was solved and that there is no alternative. (Freud 1923a, pp.308-9; my italics).

This passage suggests that there is an underlying language of dream process that is thoroughly independent of its interpretation. A dream, says Freud, "is therefore also a projection, an externalization of an internal process" (Freud 1916b, p.414). We have access to such a process by means of the psychoanalytic method of free association whereby a message can be properly decoded and its real meaning, although hidden, can be apprehended. In this way, there is an already made, already formed language behind dream images whose puzzles are waiting to be interpreted and solved.

The distinction between language and thought is the key to Wittgenstein critique to the effect that Freud would have crafted a mythology and not a proper scientific 
theory of mind. According to Wittgenstein, Freud devises a narrative full of characters with unique characteristics, just like those found in mythical ones.

\begin{abstract}
Freud refers to several ancient myths (...) and asserts that his researches explain how someone conceived of or propounded those myths. But Freud did something else. He did not offer a scientific explanation of the ancient myth. Rather, he created a new one. The attractiveness of suggestion, for example, that all anxiety is a repetition of the anxiety of the original trauma of birth and precisely the attractiveness of a mythology. 'It is all a result of something that happened a long time ago'. Almost a reference to a totem (...). There is a persuasion in saying 'yes, of course, it has to be this way'. A powerful mythology. (Wittgenstein 1982, p.9)
\end{abstract}

This criticism is associated with Wittgenstein reservations to metaphysics and to the fact that philosophical problems stem from the crisscrossing of language games. The metaphysical discourse yields a bewitchment that is highly persuasive, for it deludes the mind and undermines the proper use of language. The metaphysician is nothing but a myth maker who, with a seductive narrative, offers the solution to all problems and converts people to an all encompassing world view (cf. Wittgenstein 1969, $\S \S 92,94-7,167,612$ ). The metaphysician, or the traditional philosopher, brings out a whole class of pseudo-problems when, for example, he tries to play the language game that describes mental states by following the rules of the language games that describes physical objects. As Hacker points out, Wittgenstein holds that, by referring to mental states in the same way as we refer to external objects, the philosopher ends up devising mythologies (cf. Hacker 1996, p.110). In this way, language and reality are thought of as ontologically and epistemologically separated and the philosopher takes himself up on the task of carrying out the correspondence between them. What is worse, he presupposes that there is a language that describes with certainty the facts in the world and therefore should be distinct and privileged vis-à-vis other descriptions. Nonetheless, it is an illusion to think it is possible to devise a language like that. Metaphysicians seem unable to figure out that their philosophical systems end up changing the notation of our experiences based upon the conception of a reality completely apart from our cognitive capacities. Now, unless they can provide us with an access to that reality, such a conception is logically unsustainable. The thought of a reality that logically precedes our cognitive capacities is, after all, a thought, a conception and as such it is within the confines of those capacities (Hacker 1996, p.110).

According to Wittgenstein, Freud refers to the parts of the mind as though they were things in the world; in particular, that is the way Freud would consider the unconscious. On the face of it, there seems to be no problem in assuming that certain thoughts, desires and volitions are unconscious. The problem arises when the expression 'he unconsciously desires that...' is interpreted as meaning 'your unconscious 
desires that...', just like when we say 'I found nobody in the room' and someone thinks I am saying 'Mr. Nobody is in the room' (cf Wittgesntein 1958, p.69), just like Mrs. Gradgrind in Dickens' Hard Times states that 'there is a pain in the room' to characterize her pain. As Bouveresse points out, the

principle of mythologization lies in our need to find someone or something responsible for everything that happens; so when an action is performed 'unconsciously' and therefore cannot be attributed to the conscious subject, we are tempted to look for another author, which it is difficult not to conceive as a conscious agent (...) (Bouveresse 1995, p.34).

We have a tendency to handle the concept of the unconscious as thought it referred to a subject in the same way that we handle the concept of the conscious mind. That means we usually conceive of the unconscious as pretty much equated with the conscious, like a second subject with a mind of its own. In order to distinguish those two subjects - or those two parts of the mind - we impart a linguistic distinction to the unconscious and create a gap between the language of every day life and an alleged unconscious language. This distinction can only be achieved under the presupposition that the language of the unconscious describes things or situations that are substantially different from those every day things and situations described by the conscious mind. Once we are presented with this double world view, the temptation to impart a certain degree of unknowability to those unconscious things inevitably leads us to an ontologically distinction that is very similar to the distinction put forward by the metaphysician. That is why Wittgenstein insists the so called unconscious and conscious languages are nothing but different language games that, despite describing different things and situations, are on the same level and share the same degree of knowability.

At this juncture, we can point out a dilemma in Freud's standpoint: on the one hand, by implying there is an ontological distinction between the parts of the mind, Freud countenances the conception of an unconscious language that is unique and can only be decoded by the definitive and valid description approach provided by psychoanalysis. On the other hand, Freud can also be viewed as equating the conscious with the unconscious by maintaining it is possible to translate the language of the unconscious into the conscious one. In this way, as Wittgenstein claims, the unconscious would be merely a way of speaking, a façon de parler and its alleged uniqueness vis-à-vis the conscious part of the mind would thereby be set aside.

\section{The assent of the patient}

Wittgenstein also shows reservations to psychoanalysis by arguing that the truth value of theoretical constructs devised by the analyst is ultimately dependent upon 
the patient's assent. Indeed, Freud points that out when he comments on an example of slip of the tongue. A speaker in a party encourages everybody to toast for the boss by using the German word 'aufzustossen' (to belch) instead of 'anzustossen' (to toast). Freud claims that, although patients usually resist to accept the analyst's interpretation of this kind of mistake, their assent is absolutely necessary if the treatment is to be successful (cf. Freud 1916c, p.43). Freud adverts that the assent has to be sincere because a simple 'yes' from the patient can be construed as resistance (cf. Freud 1937b, p.49). He is well aware that confirmations from the patient have to be put into context (cf. Freud 1937b, p.50). In philosophical terms, mental states should correspond to the theories that are intent on explaining them. Now, that is precisely what Wittgenstein objects. If the criterion of truth in psychoanalysis lies in the patient's assent, then psychoanalytical explanations cannot be rendered objective and therefore true, since this assent is ultimately subjective.

Levy finds a contradiction in Wittgenstein's overall criticism of Freud. Wittgenstein faults Freud for imposing a mythological view on the patient but at the same time acknowledges that explanations in psychoanalysis can never be true because they ultimately depend upon the patient's assent (cf. Levy 1996, p. 2). Better put, the alleged contradiction consists in asserting two conflicting theses: the patient has the final word in determining the truth value of psychoanalytic propositions and the patient does not have the final word because the mythology grounding those propositions imposes itself on the patient. So either theoretical constructs depend on the reaction and the subjective assent of the patient; or they prescind with it, for they are grounded on a mythology that is devised independently of the patient's assent.

I hold, though, that this objection is flawed. The two alleged conflicting theses actually complement each other. The patient's assent is not dissociated from the persuasion to which he was subjected by the analyst and his myth-based explanations (cf. Assoun 1988, p.43). The patient can only assent to the construct provided by the analyst within the context of its corresponding mythology. In other words, the patient is ultimately led to accept psychoanalytic explanations through a method of re-education. That is precisely what Freud states when he argues that suggestion is necessary in order to break the patient's resistance. The analyst has to provide the patient with the means to bypass the layers of censorship of the conscious mind in order to have access to his repressed emotions. Psychoanalytic treatment, therefore, "is better characterized as a kind of post-education" (Freud 1916c, p.469). Freud admits that this task is only successful if the analyst is able to hold his suppositions at all costs until the patient is finally convinced to assent to them (cf. Freud 1916c, p.401).There is indeed a process of conversion that is crucial to psychoanalysis. According to Freud, the explanation per se is not enough for the success of the therapeutic process. The failure of Freud's early therapeutic endeavors consisted in the fact that the mere presentation of the problem and its roots yielded no conviction whatsoever. The patient 
has to be compelled to revive, by means of transference, past experiences that were repressed and stored in the unconscious. "[I]t is necessary to force the patient to confirm the analyst's construct (...)" (Freud 1920a, pp.16-7). Only in so doing his "conviction is acquired and (...) the therapeutic success (...)" is achieved (Freud 1920a, pp.16-7).

One could object to this line of criticism by reminding us that, although Freud insists on the persuasive nature of the psychoanalytical process, that does not mean he tries to remodel the patient's mind according to his own convenience. Once If that was so, he would be inevitably contradicted by clinical data (cf. Freud 1893, p.300). In fact, the patient himself has to arrive at his own conclusions, even when they end up conflicting with the analyst's constructs (cf. Freud 1923c, pp.226-7). Nonetheless, Freud's remarks do not preclude us from thinking that, once the patient has been properly converted to psychoanalysis, he may easily dispense with the analyst's constructs, for he will be able to elaborate psychoanalytic explanations on his own. This is confirmed by Freud himself:

In quite a number of cases, indeed, an analysis falls into two clearly distinguishable phases. In the first, the physician procures from the patient the necessary information, makes him familiar with the premises and postulates of psychoanalysis, and unfold to him the reconstruction of the genesis of his disorder as deduced from the material brought up in the analysis. In the second phase the patient himself gets hold of the material put before him; he works on it, recollects what he can of the apparently repressed memories, and tries to repeat the rest as if he were in so way living it over again. In this way he can confirm, supplement, and correct the inferences made by the physician. It is only during this work that he experiences, through overcoming resistances, the inner change aimed at, and acquires for himself the convictions that make him independent of the physician's authority (Freud 1920b, p.277).

The patient can only elaborate his own explanations after being familiarized with the main concepts and principles of psychoanalysis. Once this is done, the analyst makes sure that the patient already knows how to make inferences and to follow the rules of psychoanalytic interpretation (cf. Assoun 1988, p.64).

\section{Reasons and causes}

Wittgenstein's criticism to the effect that psychoanalytic explanations mistake motives for causes is not arbitrary and can be easily drawn from Freud's determinist inclinations to conceive of psychic phenomena as causally connected to each other, thus allowing for a scientific foundation of psychonalysis. Wittgenstein believes that Freud is unable to provide causal explanations, since psychoanalytical constructs are 
ultimately dependent upon the patient's assent. A cause "is determined experimentally" (Wittgenstein 1982, p.10). The construct to which the patient assents cannot be a cause for his laugh, but only a reason (...)" (Wittgenstein 1982, p.10). Better put, the criterion of truth for rational explanations is merely the patient's assent, while the criterion of truth for causal explanations is observation and experimentation. The first criterion cannot be tested, because the available data are ultimately private and only accessible to the patient.

One could fault Wittgenstein here for not considering that Freud does not make this distinction because rational explanations are reducible to causal ones. Davidson might be viewed as rehabilitating Freud along those lines. He states that proponents of a rigid distinction between reasons and causes generally argue that the connection between reason and action is essentially different from the connection between cause and effect. Connections of the first kind deal with internal and logical relations on the basis of which reasons are introduced with the purpose of making certain actions intelligible. In turn, connections of the second kind have to do with external, empirical relations between events in the world. According to Davidson, though, explanations of the first kind constitute a particular kind of explanations of the second kind (cf. Davidson 1980b, pp.9-10). In fact, "reason is a rational cause" (Davidson 1980c, p.233). In most cases, rational explanations may present motives as causes for their related actions.

Wittgenstein concedes there are similarities between those kinds of explanations (Wittgenstein 1953, §630). He even considers that, in certain cases, a motive can be regarded as a cause: "to present a motive of an action is like pointing out the object of fear or joy; a motive, or the object, can be viewed as a cause as well" (Wittgenstein 1979, p.83). However, what is at issue here is that a motive is not always only a cause. This point is clarified by Bouveresse:

I would be rather excessive, then, to impute to Wittgenstein the claim that the explanation by reasons and the explanation by causes are incompatible. What he does claim is that the first type of explanation is not reducible to the second. Davidson himself recognizes that there is no really satisfying way to determine what kind of cause a reason must be for one to say that it rationalizes the action. (Bouveresse 1995, pp.76-77).

Causal explanations have quite distinctive characteristics; although it is in principle possible to formulate them in a causal fashion, they will not be fully represented. In Wittgensteinean terms, we are dealing with two different language games: the one that we use in rational explanations involve intentions, desires and expectations that cannot be described by our playing the language game of causes without significant loss of meaning. Thus, although compatible in some cases, rational explanations are irreducible to causal ones at the end of the day: it is not possible do describe the in- 
tentional elements involved in rational explanations by means of the language game of causal explanations.

One could devise a reply to Wittgenstein here that goes as follows. The distinction between rational and causal explanations is based upon a false presupposition, to wit, that causal explanations in science are objective, while rational ones outside of it are not. Philosophers of science have shown this point at length throughout the twentieth century. Feyerabend, for example, argues that scientists usually resort to methods that are less than scientific to conduct their investigations, like the powerful rhetoric rendered by Galileo to justify his experimental hypotheses (cf. Feyerabend 1975). By the same token, Thomas Kuhn makes it clear that concepts, principles and the whole structure of scientific theories can only acquire meaning within the paradigm to which they belong, so that different paradigms would define and signify their main conceptions in a way that rendered them incommensurable (cf. Kuhn 1970). Bearing those considerations in mind, it seems that Wittgenstein criticism does not hold water.

I hold, however, it is possible to reply to this reservation by focussing on the method employed in science and in psychoanalysis by means of which explanations are devised. It is true the experimental method utilized in science has its problems, but Wittgenstein would insist that such a method is substantially different from the psychoanalytic method of free association. Freud explains that such a method incentives the patient to express everything that pops into his mind when presented with a certain theme or concept. In order to show how different those two methods are, and how arbitrary the method of free association is, let us take account of an example provided by Freud himself (cf. Freud 1901, pp.13ff). A young Austrian jew talks to Freud in a train. He complains about the mistreatment of jews in the Austria-Hungary Empire. He then makes a mistake while quoting the poet Virgil and states: Exoriare aliquis nostris ex ossibus ultor ("let one be born out of my bones as an Avenger"). The correct citation is: Exoriare ex nostris ossibus ultor ("let an Avenger be born out of our bones"). That means he omits aliquis and inverts the position of nostrix ex. Freud quickly identifies this as a slip of the tongue and decides to analyze the young jew. He concludes that the cause of the omission of aliquis is that he is afraid he had impregnated an Italian woman with whom he had an affair.

The association starts with the term aliquis that is successively related to others like Reliquien - Liquidation - Flüssigkeit (liquid). Afterwards, he makes a connection with Saint Simon of Trent, a child saint whose assassination was slanderously attributed to jews in the Fifteen Century. In the wake of it, the method leads to San Gennaro and the miracle of the solidified blood that liquefied. Finally, the association highlights the fact that the young jew was afraid of the interruption of a liquid flux, obviously a metaphor for the interruption of menstruation because of pregnancy. Now, would it be possible to conceive of a different starting point with the same re- 
sult? Timpanaro suggests that the same result could be achieved if the young jew had omitted exoriare, which means 'to arise'. It would not be hard to associate it with terms like 'to be born', for example. In the same way, if he had omitted ossibus, or 'bones', it would be easy to associate it with the many reliques of catholic saints and from this to a series of steps we could arrive at San Gennaro. Finally, if the young jew forgot ultor, one could arrive at Eltern, or 'parents', which in turn could lead us again to the undesirable thought of becoming a father (cf. Timpanaro 1998, p.97).

The point here is that any associative chain can lead us to a desired explanation devised by the analyst. Curiously enough, Freud is not concerned with this problem. When he is presented with a different association to the same outcome, he denies that his viewpoint is weakened (cf. Freud 1901, p. 18). It seems that, according to Freud, it does not matter what association one adopts as long as it lead us to the desired outcome. As Wittgenstein says, whenever someone is worried about something, like sex for example, it does not quite matter where to begin; the association always takes us to the same theme (cf. Wittgenstein 1966, pp.50-1). If that is the case, psychoanalytic explanations are clearly very different from scientific ones. The falling of objects must be always explained in accordance with the principle of universal gravitation and subjected to the same parameters of validation. There is no other starting point and no other criterion of truth. Now, in psychoanalysis, the same explanation may be constructed out of a manifold of different associations of ideas or premises and is validated only by the patient's assent. So, no matter which set of premises we choose, the conclusion will always be that one the patient chooses after being persuaded by the analyst. This suggests that psychoanalytic explanations carry a degree of incorrigibility that makes them rather arbitrary and pretty much dependent upon the analyst's constructs. That being the case, there is no way of contradict them after the patient's assent. Freud can then be viewed as trying to devise the definitive theory of the mind.

\section{Conclusion}

Thanks to Wittgenstein's assessments, we could unravel a number of limitations of psychoanalysis. To begin with, we could pinpoint the mythology beneath Freud's deep psychology, malgré lui. In the wake of it, psychoanalytic explanations have been shown to possess a subjective component, for it is dependent upon the patient's assent. Finally, we zeroed in on the unpalatable element of incorrigibility in psychoanalytic explanations, which led us to conclude that Freud could be seen as striving to craft a definitive conception of the mind and not just a new way of representing it.

Principia 21(1): 1-12 (2017). 


\section{References}

Allen, R.; Turvey, M. (eds.) 2001. Wittgenstein, Theory and the Arts. London: Routledge. Assoun, P.-L. 1988. Freud et Wittgenstein. Paris: Presses Universitaires de France.

Bouveresse, J. 1995. Wittgenstein Reads Freud. Princeton: Princeton University Press.

Cioffi, F. 2009. Making the Unconscious Conscious: Wittgenstein versus Freud. Philosophia 37: 565-588.

Crews, F. 1998. Unauthorized Freud: Doubters Confront a Legend. New York: Viking Press. Davidson, D. 1980a. Essays on Actions and Events. Oxford: Clarendon. 1980b. Actions, Reasons and Causes. In: Davidson 1980a, pp.9-19. 1980c. Psychology as Philosophy. In: Davidson 1980a, pp.229-244.

Eysenck, H. 1963. Uses and Abuses of Psychology. Baltimore: Penguin.

Feyerabend, P. 1975. Against Method. Londres: New Left Books.

Freud, S. 1969. Gesammelte Werke (GW). 18 v. Frankfurt: Fischer Verlag.

. 1893. Studien über Hysterie. GW I.

- 1900. Die Traumdeutung. GW II/III.

- 1901. Zur Psychopathologie des Alltagslebens. GW IV .

—. 1910. Über Psychoanalyse (Fünf Vorlesungen). GW VIII.

—. 1912. Ratschläge für den Arzt bei der psychoanalytischen Behandlung. GW VIII.

- 1913. Das Interesse an der Psychoanalyse. GW VIII.

- 1914a. Totem und Tabu. GW IX.

—. 1914b. Zur Einführung des Narzismus. GW X.

—. 1914c. Zur Geschichte der psychoanalytischenBewegung. GW X.

—. 1915. Das Unbewusste. GW X.

- 1916a. Triebe und Triebschicksale. GW X.

—. 1916b. Metapsychologische Ergänzung zur Traumlehre. GW X.

- 1916c. Vorlesungen zur Einführung in die Psychoanalyse. GW XI.

- 1919. Vorrede zu 'Probleme der Religionspsychologie' von Dr.Theodor Reik. GW XII.

- 1920a. Jenseits des Lustprinzips. GW XIII.

- 1920b. Über die Psychogenese eines Falles von weiblicher Homosexualität. GW XII.

- 1920c. Zur Vorgeschichte der analytischen Technik. GW XII.

- 1923a. Bemerkungeng zur Theorie und Praxis der Traumdeutung. GW XIII.

- 1923b. Das Ich und das Es. GW XIII .

- 1923c. Psychoanalyse und Libidotheorie. GW XIII.

—. 1925a. Die Widerstände gegen die Psychoanalyse. GW XIV .

- 1925b. Selbstdarstellung. GW XIV .

- 1933. Neue Folge der Vorlesungen zur Einführung in die Psychoanalyse. GW XV.

—. 1937a. Die endliche und die unendliche Analyse. GW XVI.

- 1937b. Konstruktionen in der Analyse. GW XVI.

- 1940. Abriss der Psychoanalyse. GW XXIII.

- 1954. The Origins of Psychoanalysis. New York, Basic Books.

Gellner, E. 1996. The Psychoanalytic Movement: the Cunning of Unreason. Evanston: Northwestern University Press.

Grünbaum, A. 1984. The Foundations of Psychoanalysis. Berkeley: University of California Press.

Principia 21(1): 1-12 (2017). 
Hacker, P. 1996. Wittgenstein's Place in Twentieth-Century Analytic Philosophy. Oxford: Blackwell.

Kuhn, T. S. 1970. The Structure of Scientific Revolutions. Chicago: The University of Chicago Press.

Levy, D. 1996. Freud among the Philosophers. New Haven: Yale University Press.

McGuinness, B. 1992. Freud and Wittgenstein. In: Wittgenstein and his Times. Oxford: Blackwell.

Moore, G. E. 1962. Wittgenstein's Lectures in 1930-3. Philosophical Papers. New York: Collier. Natsoulas, T. 1995. A Rediscovery of Sigmund Freud. Consciousness and Cognition 4: 300322.

Popper, K. 1986. The Logic of Scientific Discovery. London: Routledge.

- 1989. Conjectures and Refutations. Londres, Routledge..

Sass, L. 2001. Wittgenstein, Freud and the Nature of Psychoanalytic Explanation. In: R. Allen; M. Turvey (eds.) (2001) pp.253-295.

Tauber, A. 2010. Freud: The Reluctant Philosopher. Princeton: Princeton University Press.

Timpanaro, S. 1998. The Reign of Error. In: Crews (1998), pp.94-105.

Wittgenstein, L. 1953. Philosophical Investigations. Oxford: Blackwell.

- 1958. The Blue and Brown Books. New York: Harper Torchbooks.

- 1966. Lectures and Conversations. Oxford: Blackwell.

- 1969. On Certainty. Oxford: Blackwell.

-1978. Remarks on the Foundations of Mathematics. Oxford: Blackwell.

- 1979. Remarks on the Philosophy of Psychology. Oxford: Blackwell.

- 1982. Conversations on Freud. In: Wollheim; Hopkins (1982) , pp.1-11.

Wollheim, R.; Hopkins, J. 1982. Philosophical Essays on Freud. Cambridge: Cambridge University Press.

Marco Antonio Franciotti Federal University of Santa Catarina Department of Philosophy franciotti@icloud.com 